\title{
Smoke signals: monitoring illicit cigarettes and smoking behaviour in Colombia to support tobacco taxes
}

\author{
Norman Maldonado, ${ }^{\oplus 1}$ Blanca Llorente, ${ }^{2}$ Diego Escobar, ${ }_{1}^{3}$ Roberto Magno Iglesias ${ }^{4}$
}

'Department of Economics, International Trade and Social Policy, Universidad de Bogota Jorge Tadeo Lozano, Bogota, Colombia

${ }^{2}$ Fundación Anáas, Bogotá, Colombia, Bogota, Colombia ${ }^{3}$ FINAC, Bogotá, Colombia ${ }^{4}$ Center for Studies in Integration and Development (CINDES), Rio de Janeiro, Brazil

\section{Correspondence to} Dr Norman Maldonado, Department of Economics, International Trade and Social Policy, Universidad de Bogotá Jorge Tadeo Lozano, Bogotá 110311, Colombia;

Received 1 November 2018 Revised 31 January 2019 Accepted 17 February 2019 normanmva@gmail.com

ABSTRACT

Background A street cross-sectional survey in 2016 with a representative sample of 1697 smokers in five Colombian cities was used to estimate the penetration of illicit cigarettes (PIC). The first wave was collected 3 months before a $100 \%$ increase in tobacco excise tax, and a second wave collected data 9 months after tax reform was effective.

Objective Analyse changes after a cigarette tax increase in PIC, prices and smoking behaviour patterns for five Colombian cities ( $63 \%$ of the market). Smoking behaviour includes consumption intensity, presentation (stick/pack) and place of purchase.

Methods Repeated street cross-sectional survey with smokers' self-report on smoking behaviour, last purchase information and direct observation of smokers' packs. Sampling frame: smokers, men and women, aged 12 years or older, all income levels, resident in the five cities with the highest number of smokers representing $63 \%$ of cigarette market share (Bogotá, Medellín, Cali, Cartagena and Cúcuta) with 1733316 smokers in 2013. Sample size was 1697 per wave, with confidence level 95\%, margin of error 3.5\% for Bogotá and Medellín and 5\% for the other three cities. Smokers in second wave match first wave's location, sex and age group. Illicit cigarettes were identified based on brand, health warnings and price.

Results After the tax hike, the average real price of a 20 -stick pack increased by $28.2 \%$ and by $23.1 \%$ for loose cigarettes. Illicit cigarettes represented 3.4\% of total cigarette consumption in 2016 and increased to $6.4 \%$ in 2017 , lower than the current industry estimate of $18 \%$. Consumption intensity decreased: the proportion of heavy smokers (more than 10 cigarettes per day) wentdown from 37\% in 2016 to $26 \%$ in 2017. Conclusion After the tax increase, Colombia's PIC remained at low levels, and there is enough space for new tobacco tax hikes.

\section{INTRODUCTION}

Check for updates

(c) Author(s) (or their employer(s)) 2019. No commercial re-use. See rights and permissions. Published by BMJ.

To cite: Maldonado $\mathrm{N}$ Llorente B, Escobar D, et al. Tob Control Epub ahead of print: [please include Day Month Year]. doi:10.1136/ tobaccocontrol-2018-054820
Tobacco taxes are one of the most cost-effective policy instruments to control the tobacco epidemic. ${ }^{12}$ However, in many low-income and middle-income countries including Colombia tobacco taxes remain low. Despite the twofold increase in the cigarette (In Colombia, consumption of traditional tobacco products other than cigarettes has a negligible role, and there are no official estimates of the prevalence of new tobacco products such as electronic nicotine delivery systems. For this reason, we use tobacco and cigarettes indistinctly.) excise tax in Colombia between 2016 and 2017 from Colombian pesos
(COP\$) \$700 (US\$0.23) per 20-stick pack in 2016 to COP\$1400 in 2017 (US\$0.47), the country's average price of cigarettes remains as one of the lowest in the region. In addition, affordability in Colombia still remains stagnated, with about 84 min of work needed to buy a 20 -stick pack of cigarettes, close to values in the 90 s and 2000s, where the indicator fluctuated between 70 and 75 . Colombia's smoking prevalence has decreased over time, from $21.4 \%$ of people aged 18-69 years in 1993 to $12.9 \%$ of people aged $12-65$ years in $2013^{3}$ and $8.3 \%$ for $\geq 18$ in $2017 .{ }^{4}$ However, the country still has important inequalities on smoking prevalence across regions, age groups and gender. ${ }^{3-5}$ Together, this evidence suggests that further increases of the tobacco excise tax are needed to effectively reduce smoking prevalence and to protect new generations from the epidemic.

Big and fast new tobacco tax increases in Colombia, as recommended by the World Bank, (Marquez et al, p14) ${ }^{6}$ are opposed by the tobacco industry (TI) directly through press statements made to the media (ref 7 has an example of this strategy in other countries). In addition, indirect opposition occurs through instilling fears in policy-makers and congressmen about the ostensible adverse effects of increasing tobacco taxes, specifically, (1) the meagre effects on reducing smoking and improving public health, (2) the enormous increase of illicit cigarette trade and (3) the loss of tobacco tax revenues derived from cigarettes not paying taxes. Scientific evidence with no conflict of interest (independent) have proved these fears to be unfounded, with tobacco taxes significantly reducing tobaccoconsumption, ${ }^{8}$ raising tax revenues and not being a crucial determinant of the national consumption of illicit cigarettes. ${ }^{9}$ For the particular case of illicit cigarette trade in Colombia, TI has claimed that penetration of illicit cigarettes (PIC) in 2016, measured as the proportion of total consumption of cigarettes, is $18 \%{ }^{10-}$ a clear overestimation of the $3.45 \%$ estimated by scientific evidence from independent studies ${ }^{11}$ and a confirmation of the widely prevalent overestimation of illicit cigarettes by TI. ${ }^{12-14}$

Independent estimation of PIC served as evidence to support Colombia's tobacco tax increase in 2016 by allaying policy-makers' fears on illicit trade. ${ }^{15}$ However, substantial new increases on tobacco taxes need to be supported by evidence of the observed PIC after the tax increase in 2016. In general, the country's long-run strategy on tobacco taxes must be supported on a continual and comprehensive monitoring strategy on illicit trade and related 
variables such as prices, consumption, tax revenues and other indicators.

The purpose of this paper is to estimate Colombia's PIC after the tax increase in 2016 and analyse the evolution, before and after the tax increase, of Colombia's PIC, prices and patterns of smoking behaviour.

This paper's findings contribute to the literature by showing that large increases in tobacco taxes in a low/middle-income country (Colombia) were not followed by huge increases in illicit trade, as claimed by the TI, filling the gap of evidence on illicit trade before and after tobacco tax increases in low-income and middle-income countries. It also contributes in providing monitoring of illicit trade, prices and patterns of smoking behaviour in Colombia, highlighting the importance of a more comprehensive view of illicit cigarette trade for design of local actions on tobacco control. In addition, it proposes a method to develop comparable waves of cross-sectional street surveys on smoking behaviour.

\section{METHODS}

The study has a quantitative descriptive design. Based on primary data from the two waves (2016 and 2017) of the Demand for Illicit Cigarettes Survey (DEICS) for Colombia (COL), the study uses statistical inference to get estimates for illicit cigarette trade and statistical analysis to test for significant changes over time of illicit cigarette trade, prices and patterns of smoking behaviour. Out of all the methods for estimation of illicit cigarette trade, ${ }^{16}$ the study is a mix of two methods: survey of tobacco users and examination of cigarette packs.

\section{Data}

DEICS-COL is an independent 'street cross-sectional [face-toface] survey with smokers' self-report on consumption pattern, last purchase information and direct observation of smokers' packs [/sticks]' $\left({ }^{11}\right.$, page 1$)$. For compliance of applicable norms and standards, DEICS-COL's research protocol for both waves obtained approval from a local ethics committee.

DEICS-COL's sampling frame was the 2013 Psychoactive Substances Consumption Survey (PSCS-13), a nationally representative dataset with reliable estimates on smoking prevalence for young and adult population (age 12-65) in Colombia. The sample for DEICS-COL-2016 was restricted to the top five cities with the biggest markets of cigarettes, namely, Bogotá, Medellín, Cali, Cúcuta and Cartagena. These cities represented $57.3 \%$ of the smokers and $63 \%$ of the cigarettes in Colombia.

\section{Sample}

Sample size in DEICS-COL-2016 was 1697 smokers, and the variance for the sample design was calculated using data from studies funded by the industry. ${ }^{17}$ Sample was chosen using simple random sampling with a $95 \%$ CI for each city and margin of error of $3.5 \%$ for Bogotá and 5\% for the other cities. Expansion weights for statistical inference were calculated based on the probability of inclusion by quinquennial age groups. DEICS-COL-2016 is statistically representative of smokers in each of the five cities, and based on this sample design, eligibility criteria for participants was (1) to be a current smoker of cigarettes and (2) to match the distribution of smokers in PSCS-13 by age and gender; this excludes people smoking products other than cigarettes, children under 12 and non-residents.

Selection of participants is described by Maldonado et $\mathrm{al}^{11}$ and consists mainly of a careful selection of times (dates, day of the week and time of the day) and places visited by surveyors in each city. Once the spot was visited at a certain time, participants were selected from people smoking on public places according to the quotas of age and gender from the sample design, and data were collected from participants through individual interviews.

DEICS-COL-2016 was collected from 24 August to 14 September 2016, 3 months before the tax increase. Individuals smoking on the street were the ones selected to be interviewed, conditioned on a previous selection of space, time and quotas of age and gender for each location. The second wave, DEICS-COL-2017, was collected between 28 August and 26 September 2017, to monitor illicit cigarette trade after the tax increase and to estimate the impact of the tax increase on the size of this trade. In order to meet these goals, the sample for DEICS-COL-2017 was designed to match the sample of the first wave, raising some challenges that were addressed by a novel, tailor-made matching strategy.

The main challenge was to have comparable observations in both waves. An ideal panel would have collected data in 2017 from exactly the same smokers interviewed in 2016. However, DEICS-COL did not collect data to recontact individuals later on, mainly because the nature of the survey makes contact information for a follow-up unreliable. Contact information on household surveys or surveys at schools or workplaces is relatively reliable for two reasons. First, in those surveys, changes of person's location over time is determined by medium-term decisions such as housing, working or studying, making relocation less likely. In addition, individuals in those surveys are interviewed in an institution, either a household, a school or a company, making it possible to re-contact the institution later on to get to the person. In contrast, smoking on a particular street is a short-term decision, less likely to be related to a specific location and with no institutional environments that can be used as alternatives to contact the person, making construction of a panel in street surveys a hopeless task because of the high expected rates of attrition. The problem is exacerbated by the sensitive nature of the information collected such as smoking behaviour and socioeconomic characteristics.

The matching strategy consisted on collecting data in 2017 by visiting the same spots that were visited in 2016, approximately at the same time (date, day of the week and time of the day) and apply the same questionnaire (A short module was added at the end of the survey, asking about changes in current smoking behaviour relative to 2016 , specifically questions on changes in intention to quit, smoking intensity, place of purchase and brand.) to a smoker with similar observed characteristics (gender and approximate age) as the ones of the smoker who was interviewed on that place at that time in 2016. This matching strategy makes observations and aggregate indicators from both waves of DEICS-COL comparable. To our knowledge, DEICS-COL is the first street survey of smokers with this type of matching across waves to overcome problems of attrition in panels of street surveys. The methodology for such design is a contribution to the area of quantitative analysis of tobacco control, with the potential application of using this structure of the data for causal inference and impact evaluation.

Based on the statistical design, comparison of both waves must be interpreted as a description of the evolution of smokers of 2016 after a tax reform, and out of these smokers, only the ones who did not quit; by definition of the survey, the ones who quit are not observable. This paper focuses on describing the behaviour of estimates of aggregate indicators over time, specifically for 2016 (before tax hike) and 2017 (after tax hike); this needs the definition of a set of indicators as well as accurate inferences about the population based on the sample design 
and characteristics of the variables included in the analysis, as described in the following paragraphs. Comparisons between smokers in both waves to estimate the impact of the tobacco tax increase go beyond the scope of the paper and is left for future research.

\section{Variables}

The analysis focuses on illicit cigarette trade and related variables such as prices and smoking behaviour. The core indicator is PIC, defined as the proportion of the market that can be categorised as illicit trade. Under this definition, the market and the proportion of the market can be measured either as cigarettes (PIC-C) or as individuals smoking (PIC-I). Following previous work, ${ }^{11}$ illicit trade cigarettes were identified using smokers' self-reported price and records of characteristics of the pack, collected on examination of the smoker's cigarette pack during the interview. Using these data, illicit cigarettes were those that (1) did not have mandatory Colombia's health warnings or import/production statement, (2) have a brand not officially registered with the Tobacco Packaging and Labeling Committee in the Ministry of Health in Colombia or (3) have a price that was not high enough to pay for the excise tobacco taxes.

In Colombia, despite being banned by law, an important part of cigarettes are distributed as sticks (loose cigarettes); thus, single sticks and packs constitute two segments of the market clearly differentiated from each other. For that reason, cut-off values for the third condition were defined separately for packs and for sticks as follows: Packs of 20 cigarettes with a price lower than COP\$1700 in 2016 and COP\$2641 in 2017, and sticks with a price lower than COP\$100 in 2016 and COP\$132 in 2017 (COP\$150 because COP\$50 is the smallest denomination in Colombia's currency system). The increase of the cut-off values was calculated by adding the increase in the specific component of the excise tax from COP\$700 in 2016 to COP\$1400 in 2017, the ad valorem component of the excise tax of $10 \%$, the increase in value added tax for all goods from 16\% to $19 \%$, and a $20 \%$ margin before taxes.

Variables related to PIC are prices and smoking behaviour. Prices are the main transmission channel of tobacco taxes and, because of the oligopoly market structure, are determined by TI. Meanwhile, patterns of smoking behaviour signal how the market responds to changes in tobacco taxes. Prices are represented in the study as the average price of a cigarette, measured in nominal COP and calculated using data on total payment of last purchase, quantities bought and size of the pack. This indicator must be interpreted as the average price faced by a smoker rather than the average price of a cigarette in the market because it is not weighted by smoking intensity.

Variables on smoking behaviour include presentation, smoking frequency and intensity, expenditure, and place of purchase. In Colombia smokers get cigarettes from three presentations: single sticks, packs (10, 18 or 20 sticks) and cartons (10 packs of 20 sticks), despite of distribution of single sticks being illegal (Article 3, Law 1335/2009). This attribute of the Colombian market is important for illicit trade because the illegal nature of sticks makes it an attractive distribution channel for illicit trade, and therefore an additional variable of decision for TI to react to tobacco taxes. At the same time, consumers might choose sticks instead of packs because divisibility makes them more affordable; this effect combined with an addictive behaviour can end up in a higher expenditure on cigarettes, that might be outweighed by the decrease on smoking intensity. Participation of loose cigarettes, packs and cartons is calculated using data on presentation of the last purchase.

Smoking frequency and intensity capture the response of smoker's consumption to the tax increase. The variable for smoking frequency is the proportion of individuals self-reporting as daily smokers. Meanwhile, intensity is measured as the number of cigarettes smoked per week. It is constructed by multiplying consumption of daily smokers by seven to get cigarettes per week, and dividing consumption of less than once per week by 30 (daily consumption) and multiplied by 7 . Under this definition, intensity gives information on whether individualsended up smoking less after the tax increase. In addition, expenditure on cigarettes is calculated by multiplying smoking intensity and price, to determine whether smokers ended up spending more on cigarettes.

Finally, inference on PIC and other variables was carried out using DEICS-COL's sampling weights as expansion factors. All calculations were done in Stata/MP V.13.0.

\section{RESULTS}

Table 1 shows the estimates of PIC-I and PIC-C for 2017 as well as the comparison with estimates for 2016 to see the evolution of illicit cigarettes before and after the tax increase.

The proportion of individuals smoking illicit cigarettes in these five cities increased by 0.88 percentage points (pp), from $3.35 \%$ to $4.23 \%$, and the increase was statistically significant at $5 \%$. This was mainly caused by the considerable and statistically significant increase in smokers of illicit cigarettes in Cúcuta. Bogotá is the only city where PIC-I decreased, although the lack of statistical significance for this and all remaining cities does not allow to conclude on changes over time.

Moving to PIC-C, there was a statistically significant increase in the aggregate of the five cities from $3.46 \%$ to $6.37 \%$. This has caused mainly by a decrease in the number of cigarettes, which in turn, as the results for smoking patterns show, is caused by a lower smoking intensity. The number of cigarettes in the sample decreased, from 89090 cigarettes per week in 2016 to 78073 in 2017; by expanding these values using sampling weights, the annual estimate of cigarettes in 2016 was 4921.15 million (equivalent to 246.05 million packs of 20 sticks), and decreased by $16.6 \%$ to 4099.96 in 2017 (equivalent to 204.99 million packs). This effect, combined with the small increase in smokers of illicit cigarettes shown in PIC-I, led to statistically significant increases of PIC-C overall.

Comparison of cities shows not only important differences in PIC among them before the tax (as previously noted in DEICS-COL-2016 $6^{11}$ ) but also heterogeneity in PIC's variation after the tax increase. Variations in Bogotá were moderate, with a reduction of $1.54 \mathrm{pp}$ in PIC-I and an increase of $0.46 \mathrm{pp}$ in PIC-C. The opposite occurred to Cúcuta, the city with both the highest PIC and the largest increase over time, close to a twofold increase in PIC-I and PIC-C.

Increase in tobacco taxes have a direct effect on prices; since prices are systematically different for packs and loose cigarettes, figures 1 and 2 show the evolution of prices for these two segments respectively, measured as price per cigarette in nominal COP\$. The average price of a cigarette from a pack (figure 1) increased $32.2 \%$, from COP\$189.2 to COP\$250.1. To express this result in real units, we used a $3.97 \%$ inflation for that period, based on the variation of Consumer Price Index between September 2016 and September 2017 reported by the Central Bank of Colombia. The real increase in price for packs was $28.2 \%$. As for loose cigarettes (figure 2), the average price 
Table 1 Evolution of PIC

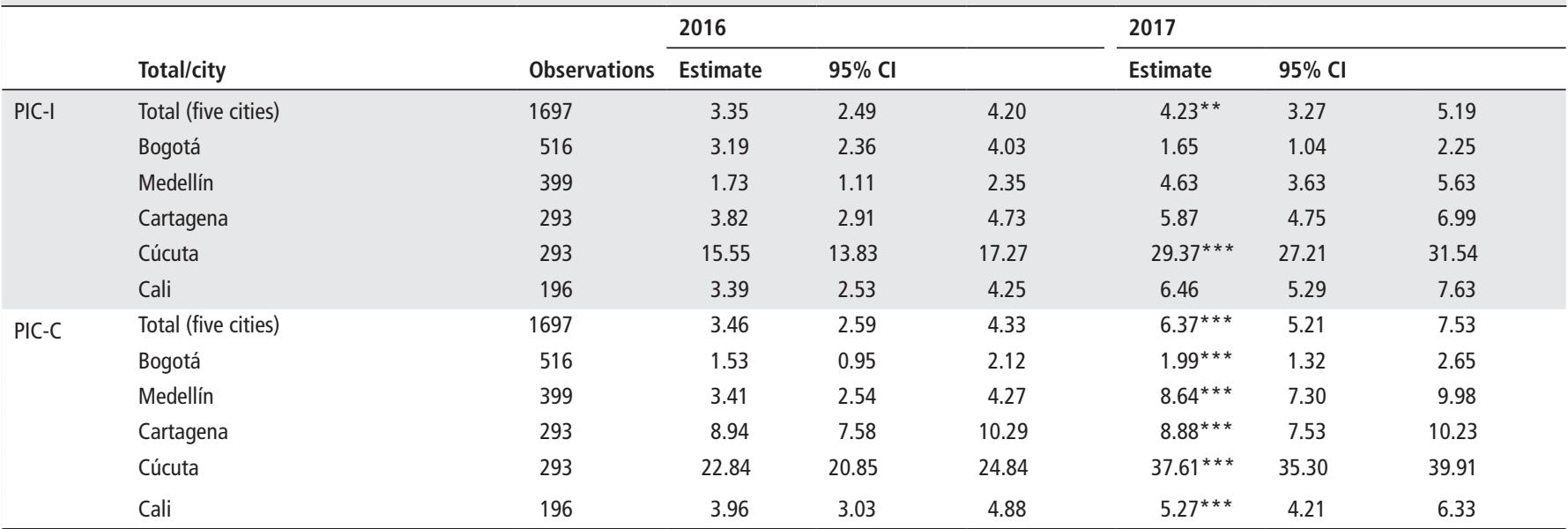

Estimates based on DEICS-COL-2016 and DEICS-COL-2017. Cls estimated using a normal approximation. 1697 observations per year, representing 1733316 smokers. $\left({ }^{*}\right)$ denotes statistically significant difference between both waves at $10 \%, 5 \%\left({ }^{* *}\right)$ and $1 \%\left({ }^{* *}\right)$, using a two-tailed test for comparison of two proportion populations with no sampling weights.

COL, Colombia; DEICS, Demand for Illicit Cigarettes Survey; PIC, penetration of illicit cigarettes; PIC-C, PIC as the proportion of the consumption of cigarettes; PIC-I, PIC as the proportion of individuals (smokers).

increased $27.1 \%$ from COP\$337.3 to COP\$428.6, with a real increase of $23.1 \%$. The difference in average prices between years is significantly different from zero at $1 \%$ confidence level for both nominal and real prices.

Figures 1 and 2 also show that distribution of prices is not normal, a result confirmed by the Shapiro-Wilk test. Kurtosis increases from 5 in 2016 to 10.89 in 2017 for packs, while for single sticks the increase is smaller, from 3.82 in 2016 to 4.03 in 2017. These results suggest that the tobacco tax hike does not only shifts the distribution to the right as expected, but also changes the shape of the distribution by extending the range of prices, especially in expensive cigarettes. Due to the small number of illicit cigarettes found in DEICS, there is no enough statistical power to perform a similar analysis stratified by licit/illicit cigarettes. Despite of that limitation, it is important to mention that illicit cigarettes were found along all the range of prices in both loose cigarettes and packs, which means that illicit cigarettes are not necessarily the cheapest ones.

Regarding presentation of cigarettes, the proportion of smokers who bought single sticks in their last purchase increased from $57.8 \%$ in 2016 to $68.8 \%$ in 2017 , with the subsequent

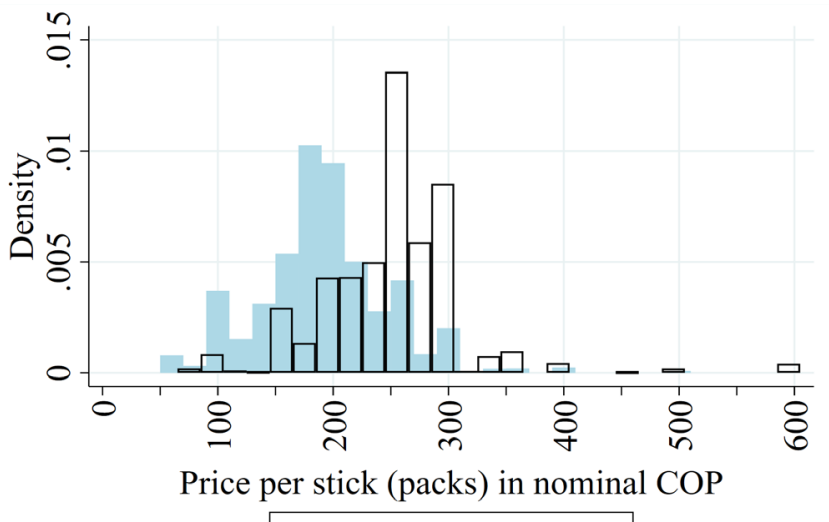

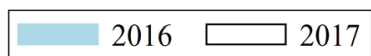

Note: 2 atypical $(>=1000)$ observations were dropped reduction in packs from $41.7 \%$ to $30.5 \%$, and a negligible participation of cartons. When these proportions are calculated for cigarettes, both single sticks and cartons increased their participation: single sticks from $9.1 \%$ in 2016 to $14 \%$ in 2017 , and cartons from $14 \%$ to $20 \%$; meanwhile, packs decreased from $76.9 \%$ to $65.1 \%$. All these changes over time are statistically different from zero at $1 \%$ confidence level.

Most smokers bought their cigarettes from informal corner stores or street vendors. The proportion of smokers getting cigarettes from informal corner stores had a non-statistically significant decrease from $40 \%$ in 2016 to $38 \%$ in 2017 . In contrast, that from street vendors had a statistically significant increase (at $1 \%$ ) from $50.9 \%$ to $55.8 \%$. Participation of supermarkets, which represent formal distribution channels, is low, with $6.2 \%$ of smokers getting cigarettes from them in 2016 and $4.5 \%$ in 2017. Other distribution channels have negligible participation in the market.

Smoking frequency remained stable over time. The proportion of daily smokers went down from $85.1 \%$ in 2016 to $79.5 \%$ in 2017 , and the difference is not statistically significant. Meanwhile, after the tax increase, smoking intensity decreased.

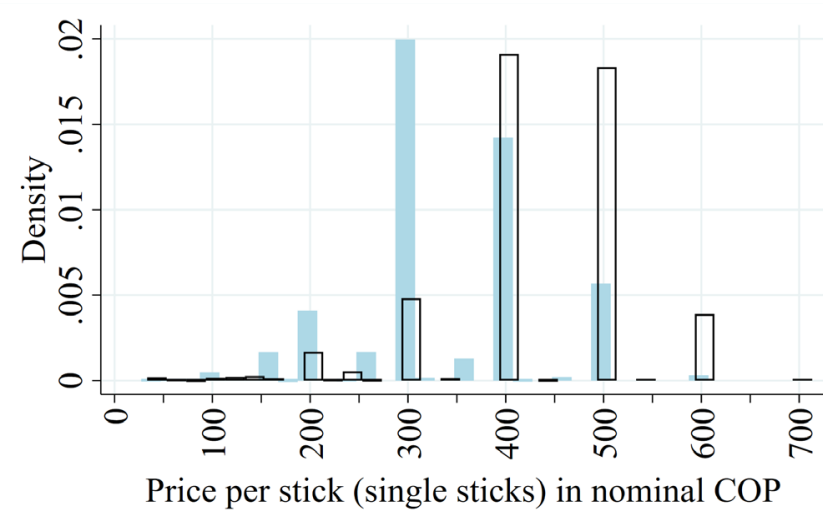

\begin{tabular}{|l|l|}
\hline $2016 \quad \square$ & $\square 17$ \\
\hline
\end{tabular}

Note: 1 atypical ( $>=1000)$ observation was dropped

Figure 1 Evolution of the price of packs. COP, Colombian peso.

Figure 2 Evolution of the price of single sticks. COP, Colombian peso. 


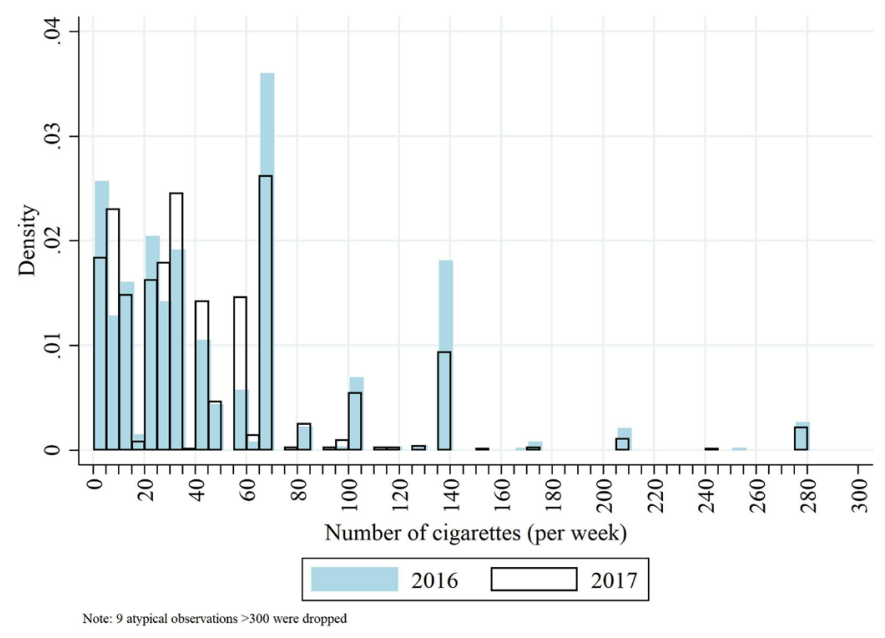

Figure 3 Evolution of smoking intensity. COP, Colombian peso.

Figure 3 compares the distribution of smokers by smoking intensity for both years; the distribution shifts to the left, suggesting that smokers move from high intensities $(\geq 70$ cigarettes per week) to low intensities $(<70)$. The drop in the lowest interval (0.5) might be explained by quitting after the tax, a hypothesis that cannot be tested with DEICS-COL as it does not include ex-smokers. Decreasing intensity is confirmed by the $17.4 \%$ drop in the average number of cigarettes per week, from 53.4 cigarettes per week (nearly 2.7 packs of 20 sticks) in 2016 to 44.1 (2.2 packs) in 2017, with a statistically significant difference (at $1 \%$ ) between these means.

Expenditure on cigarettes combines the effect of higher prices with the reduction on smoking intensity. The average nominal expenditure on cigarettes grew by $12.2 \%$ from COP\$ 13121.8 per week in 2016 to 14726.3 in 2017, while the real increase was 7.9\% (average expenditure in 2016 measured in 2017 units is COP\$13 642.79). The change in real expenditure is significantly different from zero, suggesting that the effect of reduction in smoking overcame the effect of prices which is supported by the price-inelastic nature of tobacco consumption. Also, expenditure has a right-skewed distribution with a long right tail, making the median a more accurate statistic to describe its behaviour. The median expenditure for 2016 was COP\$10 500 and for 2017 was COP\$1 200, with a nominal and real increase of $6.6 \%$ and $2.6 \%$, respectively.

\section{DISCUSSION}

Results indicate that illicit cigarette trade in the top five markets for cigarettes in Colombia remains in moderate levels after an important increase in tobacco excise tax. Despite the increase in illicit cigarette trade, the public health benefits and the additional tax revenues largely surpass the loss on tax revenue from additional illicit trade.

The case of Bogotá is exceptional because it has the lowest PIC and at the same time it is the biggest market in the country. One possible explanation is that institutions are stronger as compared with other cities. In addition, Colombia is not an attractive market for illicit trade because price of cigarettes is low compared with other neighbouring countries, which implies that Colombia is not the final destination but a transit point to access other markets, and for that reason multinational actions and coordination is necessary to advance the tobacco tax agenda in Latin America.
Continual monitoring allowed to compare prices before and after the tax increase. Results on prices suggest there is evidence on overshifting (ie, prices rise by more than the $\operatorname{tax})^{18}$ : the increase of COP\$700 per 20-stick packs corresponds to an increase of COP\$35 per cigarette. However, the price of a cigarette increased by COP\$60.9, almost twice the expected value.

The findings on illicit trade presented in this paper have some limitations. First, the survey only covers the main five markets in the country. However, other markets are expected to have a similar behaviour because they have similar smoking prevalence and cities included here capture the heterogeneity of subnational conditions in the country. Also, despite of DEICS analysing only urban areas, there is evidence showing that smoking behaviour in Colombia is similar in rural areas. Additional waves of DEICS with wider coverage are necessary to support these statements.

Second, inference cannot be made for combinations of illicit trade and smoking behaviour, such as smoking intensity discriminated by licit/illicit cigarettes. This occurs because of the sample design and the low number of cases of illicit trade, both undermining the statistical power of such stratification. Expansion of the sample size in future research seems to be one reasonable way to gain further knowledge of the dynamics of illicit trade and smoking behaviour.

What this paper adds

What is already known on this subject

- Tobacco taxes are the most cost-effective policy tool to stop the tobacco epidemic.

- New tobacco tax increases are being blocked by fears of taxes leading to an upsurge of illicit trade which in turn would undermine the public health effect of the tobacco tax and generate losses in tobacco tax revenues. These fears are fed by biased overestimates of the penetration of illicit cigarette trade by TI.

- Previous independent estimates show an important overestimation of illicit cigarette trade by $\mathrm{TI}$.

What important gaps in knowledge exist on this topic

- There are no previous estimates for Colombia on illicit cigarette trade before and after a tax hike, so the gap it fills is evidence on changes on this trade before and after tobacco tax increases.

- Colombia does not have independent monitoring of illicit cigarette trade and patterns of smoking behaviour before and after tax increases. The paper fills the gap of monitoring illicit cigarette trade, prices and smoking behaviour using a set of indicators that can be used to support further tobacco tax increases.

- The paper proposes a novel method to build comparable individuals on multiple waves of street surveys on smoking behaviour. The method is a solution to overcome high levels of attrition associated with follow-ups of street surveys and collection of sensitive data such as patterns of smoking consumption.

What this study adds

- After a twofold increase in tobacco excise tax in Colombia, penetration of illicit cigarettes remained at moderate levels.

- The increase in illicit trade in Colombia after a symmetric nationwide tobacco tax hike was asymmetrical across regions, suggesting that regional factors can explain illicit trade better than tobacco taxes. 


\section{CONCLUSIONS}

Despite a twofold increase in the tobacco excise in the main five markets for cigarettes in Colombia and a 2.9 pp increase in illicit trade, overall illicit cigarette trade is still low, and substantially lower than TI's estimates. ${ }^{10}$ TI claimed that PIC-C increased by 5 pp from $13 \%$ in 2016 to $18 \%$ in 2017, while estimates from DEICS showed an increase of 2.9 pp from 3.46 to 6.37 ; as for PIC-I, TI's estimates claim an increase of 4 pp from $9 \%$ to $13 \%$ while independent estimates showed a small increase of $0.88 \mathrm{pp}$ from 3.35 to 4.23 . Policies must be based on unbiased and independent evidence for them to be protected from TI's interests (1, Article 5.3). Further independent research is needed to take down biased evidence from TI.

The low value of PIC after a tax increase suggests illicit trade should not be an obstacle for further increases in the tobacco excise. These increases are necessary to reach the country's targets on Sustainable Development Goals on premature mortality from non-communicable diseases.

There are important differences across cities, and the findings show that Cúcuta, a city located at the border with Venezuela, has the highest PIC and PIC's increase, suggesting that border cities need stronger institutions and actions to control illicit trade, including development of economic activities that do not rely on illicit trade of goods. In general, asymmetrical expansion of PIC across cities after a homogeneous tax increase is evidence on tobacco taxes and prices not being the main determinants of illicit cigarette trade. Instead, tobacco tax increases must be complemented with decisions from multiple sectors to reach approval and accurate implementation of the Protocol to Eliminate Illicit Trade, in particular, independent tracking and tracing systems and actions on strengthening local institutions to control illicit trade, especially in border regions.

Distribution of single sticks are a major issue in Colombia. Even though loose cigarettes are, on average, more expensive than cigarettes from packs, this effect is counteracted by the divisibility they offer, which at the end, makes cigarettes more affordable. Also, illicit cigarettes are mainly distributed through informal channels such as street vendors or corner stores. Thus, enforcement of the banning of selling loose cigarettes must be a prioritised multisectoral intervention to support tobacco control policies.

Finally, success of tobacco control policies in the long run requires a continual and comprehensive monitoring system. This system should centralise information, use the most reliable data and minimise asymmetries of information among policy-makers and stakeholders of these policies. This paper is a first step of basic monitoring to support tobacco tax policies.

Contributors NM: conceived and designed the study, led data analysis and interpretation and drafted and edited the paper. BLl: conceived and designed the study, performed data analysis and interpretation, drafted and edited the paper and responsible for final approval of the paper. RMl: advised on study design and revised the manuscript. DE: responsible for sample design, revised the manuscript and responsible for primary data collection. All four authors take responsibility for the content of the paper.

Funding This study was funded by American Cancer Society (TAAGBTACRUK) and Cancer Research UK (TAAGBTACRUK).

Competing interests None declared.

Patient consent for publication Not required.

Provenance and peer review Not commissioned; externally peer reviewed.

\section{REFERENCES}

1 WHO. WHO framework convention on tobacco control. Geneva: World Health Organization (WHO), 2004.

$2 \mathrm{NCl}, \mathrm{WHO}$. The economics of tobacco and tobacco control. National Cancer Institute (NCI), World Health Organization (WHO), 2016

3 MinJusticia, MinSalud, O.D.C. Estudio Nacional de Consumo de Sustancias Psicoactivas enColombia 2013. Bogotá: Ministerio de Justicia y del Derecho (MinJusticia), Ministerio de Salud y Protección Social (MinSalud) y Observatorio de Drogas de Colombia (O.D.C.), 2014.

4 DANE. Boletín técnico Encuesta Nacional de Calidad de Vida (ECV) Año 2017. Departamento Administrativo Nacional de Estadística (DANE), República de Colombia 2017.

5 MinJusticia, O.D.C, MinEducaion, Minsalud. Estudio Nacional de Consumo de Sustancias Psicoactivas en población escolar - Colombia 2016. Ministerio de Justicia y del Derecho (MinJusticia), Observatorio de Drogas de Colombia (ODC), Ministerio de Educación Nacional (MinEducacion), Ministerio de Salud y Protección Scoail (MinSalud), 2016.

6 Marquez P, Moreno-Dodson B. Tobacco Tax reform at the crossroads of health and development: a Multisectoral perspective. World Bank, 2017.

7 Rowell A, Evans-Reeves K, Gilmore AB. Tobacco industry manipulation of data on and press coverage of the illicit tobacco Trade in the UK. Tob Control 2014;23:e35-43.

8 HHS. The health consequences of smoking - 50 years of progress. a report of the surgeon general. U.S. Department of Health and Human Services (HHS), 2014.

9 Gilmore $A B$, Reed $\mathrm{H}$. The truth about cigarette price increases in Britain: Table 1. Tob Control 2014;23:e15-16.

10 INVAMER, ANDI. Incidencia de cigarrillos ilegales en Colombia. Investigación y Asesoría de Mercado (INVAMER), Asociación Nacional de Empresarios de Colombia (ANDI), 2017.

11 Maldonado N, Llorente BA, Iglesias RM, et al. Measuring illicit cigarette Trade in Colombia. Tob Control 2018. doi:10.1136/tobaccocontrol-2017-053980. [Epub ahead of print: 14 Mar 2018].

12 Paraje G. Illicit cigarette Trade in five South American countries: a gap analysis for Argentina, Brazil, Chile, Colombia, and Peru. Nicotine Tobacco Research 2018;3:nty098.

13 Gilmore AB, Rowell A, Gallus S, et al. Towards a greater understanding of the illicit tobacco trade in Europe: a review of the PMI funded 'Project Star' report". Tobacco Control 2013.

14 Chen J, McGhee SM, Townsend J, et al. Did the tobacco industry inflate estimates of illicit cigarette consumption in Asia? An empirical analysis. Tob Control 2015;24:e161-7.

15 Garcia MI, Villar M, lunes R. The political economy of the 2016 tobacco and proposed sugar-sweetened beverage Tax increases in Colombia. The World Bank, 2017.

16 Ross H. Understanding and measuring cigarette Tax avoidance and tax evasion. A methodological guide. Prepared for the Economics of Tobacco Control Project, School of Economics, University of Cape Town, Tobacconomics, Health Policy Center, Institute for Health Research, and Policy, University of Illinois at Chicago, 2015.

17 FND, INVAMER. Incidencia de cigarrillos ilegales en Colombia. Federación Nacional de Departamentos (FND), Investigación y Asesoría de Mercadeo (INVAMER), 2015.

18 Gilmore AB, Tavakoly B, Taylor G, et al. Understanding tobacco industry pricing strategy and whether it undermines tobacco Tax policy: the example of the UK cigarette market. Addiction 2013;108:1317-26. 